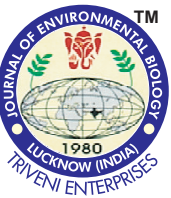

DOI : http://doi.org/10.22438/jeb/39/5/MRN-615

\title{
Interactive effects of gibberellic acid and salt stress on growth parameters and chlorophyll content in oat cultivars
}

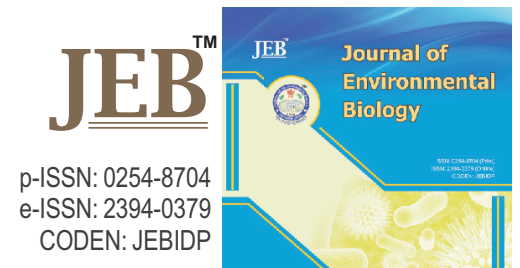

\section{Authors Info}

Anju Chauhan ${ }^{1 *}$, Nidhi Rajput', Ashok Kumar', J.S. Verma and A.K. Chaudhry'

'Department of Botany, School of Sciences, IFTM University, Moradabad-244 001, India

${ }^{2}$ Department of Genetics and Plant Breeding, G.B. Pant University of Agriculture and Technology, Pantnagar-263 145, India

*Corresponding Author Email : anjuchauhan696@gmail.com

Key words

Chlorophyll content

Gibberellic acid

Oat cultivars

Seedling growth

Salinity stress

Publication Info

Paper received : 15.03 .2017

Revised received: 02.11 .2017

Re-revised received : 21.12 .2017

Accepted: 27.12 .2017

\section{Abstract}

Aim: The main objective of this study was to evaluate the possible mode of interaction between salinity and application of gibberellic acid $\left(\mathrm{GA}_{3}\right)$ and exploring how $\mathrm{GA}_{3}$ can mitigate the harmful effects of salinity. On the basis of reduction, growth parameter and chlorophyll contents, the cultivars were categorized as tolerant, moderate and sensitive.

Methodology: To determine the effect of salinity on seed germination, seedling growth and chlorophyll contents pot experiment was carried out. Three different varieties (UPo-212, NDO-2 and UPO-94) were germinated under four different salinity levels $(25,50,75$ and $100 \mathrm{mM})$. After $24 \mathrm{hrs}$., two sets of each were treated with 100 ppm of $\mathrm{GA}_{3}$ (reused for 15 days).

Results: The results revealed that when seedling were treated with $\mathrm{GA}_{3}$ under different salinity conditions, cv. NDO-2 and UPO-212 showed better growth and high chlorophyll content than cv. UPO-94. This study conducts that $100 \mathrm{ppm}$ concentrations of $\mathrm{GA}_{3}$ will be able to overcome the toxic effects of salt stress in seed germination, seedling growth and chlorophyll contents.

Interpretation: The study reveals that application of $\mathrm{GA}_{3}$ is useful to mitigate salinity stress and is more effective on salt tolerant cultivars.

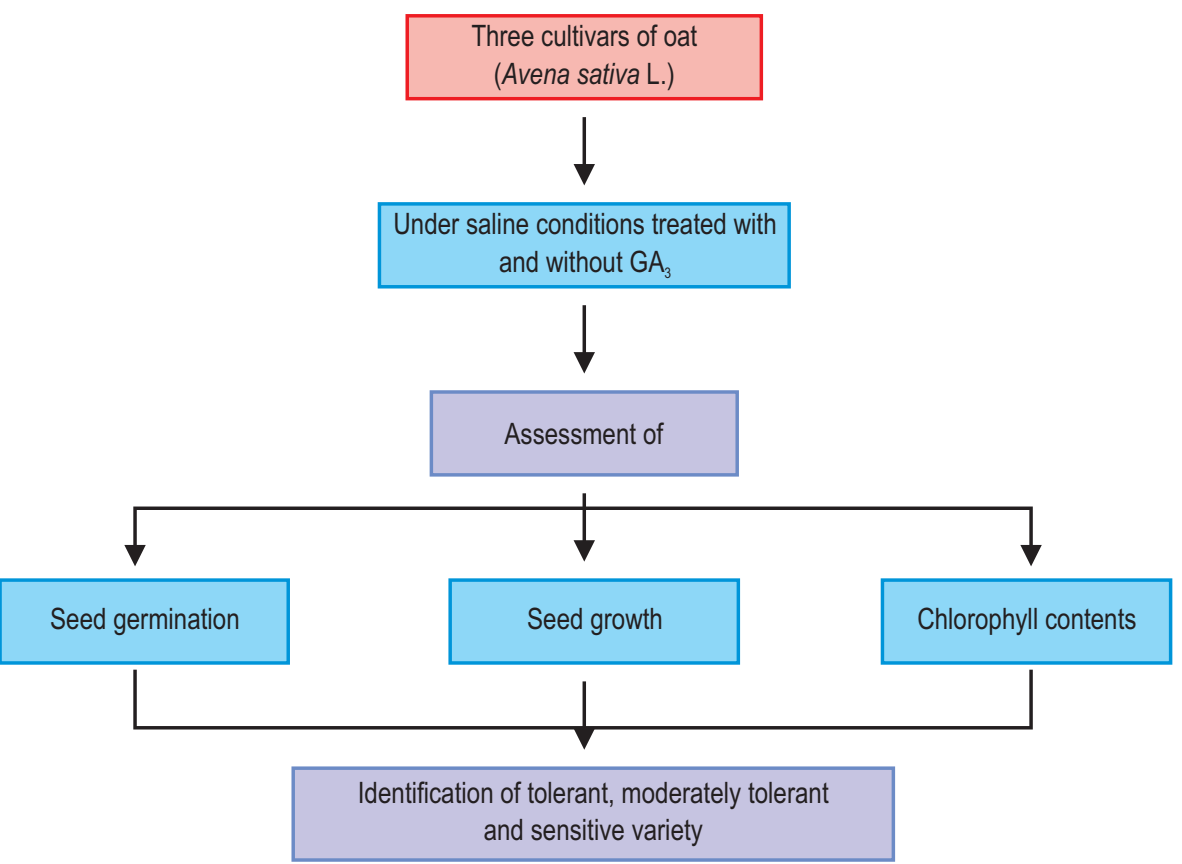




\section{Introduction}

Oat is a winter cereal crop which ranks sixth in world cereal production following wheat, maize, rice, barley and sorghum. It is multipurpose crop which is grown for grain, forage and crop rotation. Oat is grown in temperate zone as rabi crop and requires low heat and has high tolerance tolerance towards rain than other cereals, such as barley, wheat or rye (Pandey and Roy, 2011).

Salinity is one of the adverse environmental factors limiting the productivity of crop plants because most of the crop plants are sensitive to salinity. It was estimated that about $20 \%$ (45 million ha) of irrigated land, producing one-third of the world's food which is affected by salinity (Shrivastava and Kumar, 2015). Thus, it is a serious threat to agricultural productivity, especially in arid and semi-arid region (Parvaiz and Satyawati, 2008). The harmful effects of salinity can be minimized by application of various chemicals mainly Phytohormones i.e., auxins, cytokinins, brassinosteroids, Gibberellic acid $\left(\mathrm{GA}_{3}\right)$ etc. $\mathrm{GA}_{3}$ are plant growth regulators that are also known to induce various physiological responses in plants (Chauhan et al., 2015), which is most favourable for promoting and improving plant growth and photosynthetic activity (Jasmine and John, 2012). GA is used to regulate plant growth by increasing cell division and cell elongation. $\mathrm{GA}_{3}$ also maintains different biochemical properties in plants and improves grain yield (Seckin et al., 2009).

Salinity affects photosynthesis by decreasing $\mathrm{CO}_{2}$ availability as a result of diffusion limitations (Flexas et al., 2007) and reduction in contents of photosynthetic pigments (Ashraf and Harris, 2013). Reduction of chlorophyll content due to salinity stress is common in salt-sensitive plant species which cause burning of leaves and other succulent parts and degradation of pigments, however, saline tolerant species that can protect themselves from such deterioration of salinity stress. Decreased level of chlorophyll has been reported in (Jallel et al., 2008) in Catheranthus roseus; (Akca and Samsunlu, 2012) in Juglans regia, it has due to enzymatic chlorophyll degradation. Salinity, in general, has inhibitory effects on germination of seeds (Zhang et al., 2010; Kaveh et al., 2011; El-Sabagh et al. 2016) due to hyperosmotic stress and hyper-ionic toxicity (Hasegawa et al., 2000). Seedlings are the most vulnerable stage in the life cycle of plants and germination determines when and where seedling growth begins (Baskin and Baskin, 2014; Gioria et al., 2016). Increased salinity caused a significant reduction in germination percentage, germination rate, root and shoot length and fresh weight of root and shoot (El-Shaieny, 2015).

Considering the trends of growth reduction due to salinity and progressive impact of exogenous $\mathrm{GA}_{3}$ application on different morphological, physiological and biochemical activities, it can be stated that application of $\mathrm{GA}_{3}$ is useful to mitigate salinity stress and its effectiveness is more dynamic to salt tolerant cultivar
(Misratia et al., 2015). The evidence for hormone involvement comes from correlation of hormone concentration with specific development stages, effects of applied hormones and relationship of hormones to metabolic activities. The application of $\mathrm{GA}_{3}$ increases the plant growth by attributing the fact that they increase the amino acid content in embryo and induces the syntheses of hydrolytic enzyme required for digestion of endospermic starch when seeds renew growth at germination (Jasmine and John, 2012).

The aim of this research was studying GA3 effect on seed germination, early growth and chlorophyll content of oat cultivars under salinity stress.

\section{Materials and Methods}

To study the response of oats to $\mathrm{GA}_{3}$ during salt stress a pot experiment was carried out. Sand culture method was applied to test the interactive effects of salinity and $\mathrm{GA}_{3}$ on oat cultivars. Three oat cultivars NDO-2 from Narendra Dev University of Agriculture \& Technology, Faizabad (U.P.), UPO-212 and UPO94 were procured from G.B. Pant University of Agriculture and Technology, Pantnagar (Uttarakhand) for performing the experiment.

The germination count was recorded at alternate day until germination stoped. The length, fresh weight of roots and shoots were recorded at 15 days (approximately) after sowing. Shoot and root length were recorded by taking average of three plants in each treatment. Plants harvested from each treatment were washed with water to eliminate the contamination. Water was soaked with blotting paper. Root and shoot of plant selected from each treatment was separated carefully and their fresh weight was measured with the help of an electronic balance. The germination percentage was calculated.

Chlorophyll content in fresh leaves was determined at seedling stage ( 15 days after germination) to assess interactive effect of salinity and $\mathrm{GA}_{3}$ on chlorophyll contents. The chlorophyll content was estimated following the method of Arnon (1949).

Statistical analysis: Data presented is mean values from two independent experiments (with and without $\mathrm{GA}_{3}$ ) each with three replicates. Experimental data were analyzed with the SPSS Statistical Computer Package (SPSS for WINDOWS, Standard Version 20.0) with PStT (Paired Sample t- Test) at $P=0.05 \%$ level.

\section{Results and Discussion}

The interactive effects of salinity and $\mathrm{GA}_{3}$ on seed germination of oat cvs. (NDO-2, UPO-212 and UPO-94) is shown in Fig.1. The statistical analysis (Paired sample t-test) indicates that seed germination was significantly affected in cvs. NDO-2 and UPO-94, except in UPO-212 with respect to all salinity levels 
(Table 1). Salinity, in general case, has inhibitory effect on germination of seeds (Akbarimoghaddam et al., 2011) in wheat and oat species (Zhang et al., 2013). The cv. UPO-212 exhibited maximum percentage germination at all levels of salinity including control, but minimum reduction was achieved by cv. NDO-2 in both the case. At high salinity levels (75 and $100 \mathrm{mM})$, higher reduction (46.86 to $56.36 \%$ ) was achieved in cv. UPO-94 and least reduction (26.64 to $36.02 \%$ ) in NDO-2 followed by UPO-212 (37.90 to $47.33 \%$ ). Present results indicate that the percentage germination reduced significantly with increase in saline concentration in oat cultivars. Similar results were reported earlier by Kumar et al. (2014); Chauhan et al. (2016) and Benlioglu and Ozkan (2016) in oats. Exogenous application of $\mathrm{GA}_{3}$ through foliar or presoaking seed is good option to alleviate the adverse effect of salinity stress on crops (Ashraf et al., 2008). The increased germination percentage in $\mathrm{GA}_{3}$ treated seeds might be attributed to fact that the $\mathrm{GA}_{3}$ helps in breaking the seed dormancy which results in early and enhanced seed germination due to the diffusion of endogenous auxin and gibberellins like substances (Gurung et al., 2014). $\mathrm{GA}_{3}$ reduces the harmful effects of salinity on germination. When seeds were treated with $\mathrm{GA}_{3}$, cv. UPO-94 exhibited maximum reduction (17.92 to $48.13 \%$ ) while minimum reduction (7.20 to $26.87 \%$ ) was found in cv. NDO-2 respectively at all salinity levels (25 to $100 \mathrm{mM}$ ). Tolerant cv. NDO-2 revealed higher germination percentage while sensitive cultivar UPO-94 showed low germination under different salinity levels (with and without $\mathrm{GA}_{3}$ ). $\mathrm{GA}_{3}$ has been reported to increase germination percentage and overcome the preventive effects of the salt stress on germination (Ghodrat and Rousta (2012). A few studies have, however, demonstrated the ability of foliar pretreatment with $\mathrm{GA}_{3}$ to overcome effects of salt stress (Patel and Mankad (2014).

Effect of salinity and $\mathrm{GA}_{3}$ on length of shoot and root showed decreasing trend with increasing levels of salinity. However, application of $\mathrm{GA}_{3}$ alleviated the negative effects of salinity since the above mentioned characters were significantly increased. The inhibitory effect was more pronounced in root than shoot in both groups (Fig. 2 a, b). Under salinity treatment, higher reduction (18.17 to $51.01 \%$ and 23.52 to $57.76 \%$ ) was observed in variety UPO-94 and lesser reduction (12.90 to $37.60 \%$ and 15.80

Table 1 : Effect of $\mathrm{GA}_{3}$ and salinity stress on different cultivars of oat

\begin{tabular}{|c|c|c|c|c|c|}
\hline \multirow[t]{2}{*}{ Cultivars } & \multicolumn{5}{|c|}{ Mean difference ( with $\mathrm{GA}_{3-}$ without $\mathrm{GA}_{3}$ ) } \\
\hline & Germination \% & Shoot length $(\mathrm{cm})$ & Root length (cm) & Fresh weight of shoot (mg) & Fresh weight of root (mg) \\
\hline NDO-2 & $9.23 \pm 2.09^{*}$ & $6.56 \pm 0.32^{*}$ & $3.77 \pm 0.14^{*}$ & $13.13 \pm 6.96^{*}$ & $10.61 \pm 4.36^{*}$ \\
\hline UPO-212 & $5.29 \pm 4.85^{\mathrm{ns}}$ & $5.05 \pm 0.13^{*}$ & $2.53 \pm 0.10^{*}$ & $10.64 \pm 4.06^{*}$ & $8.03 \pm 3.09^{*}$ \\
\hline UPO-94 & $4.46 \pm 0.84^{*}$ & $3.19 \pm 0.41^{*}$ & $1.39 \pm 0.15^{*}$ & $6.14 \pm 3.03^{*}$ & $6.87 \pm 2.04^{\mathrm{ns}}$ \\
\hline
\end{tabular}

Values are mean of four replicates \pm SD; Data subjected to paired sample 't' test; ${ }^{(*)}$ significant at 0.05 level; ${ }^{\text {(n) })}$ non-significant

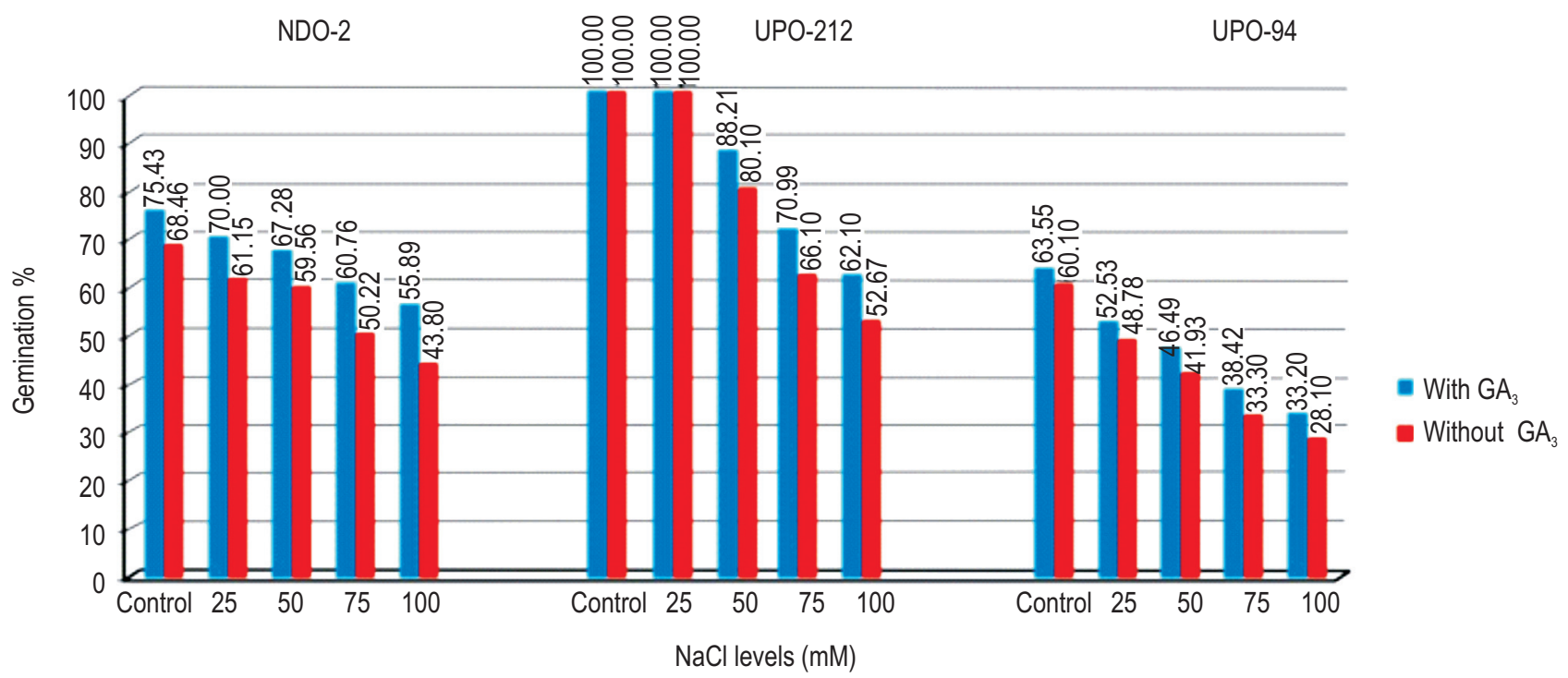

Fig. 1 : Interactive effects of salinity and $\mathrm{GA}_{3}$ on germination $\%$ on three cultivars of oat; (Without $\mathrm{GA}_{3}$ all treatment $(25,50,75 \mathrm{and} 100 \mathrm{mM} \mathrm{NaCl}$ concentrations) was compared with control; $\mathrm{GA}_{3}+$ salt treatment was compared with $\mathrm{NaCl}$ treatment. Application of $\mathrm{GA}_{3}$ significantly promoted the germination percentage under saline conditions) 

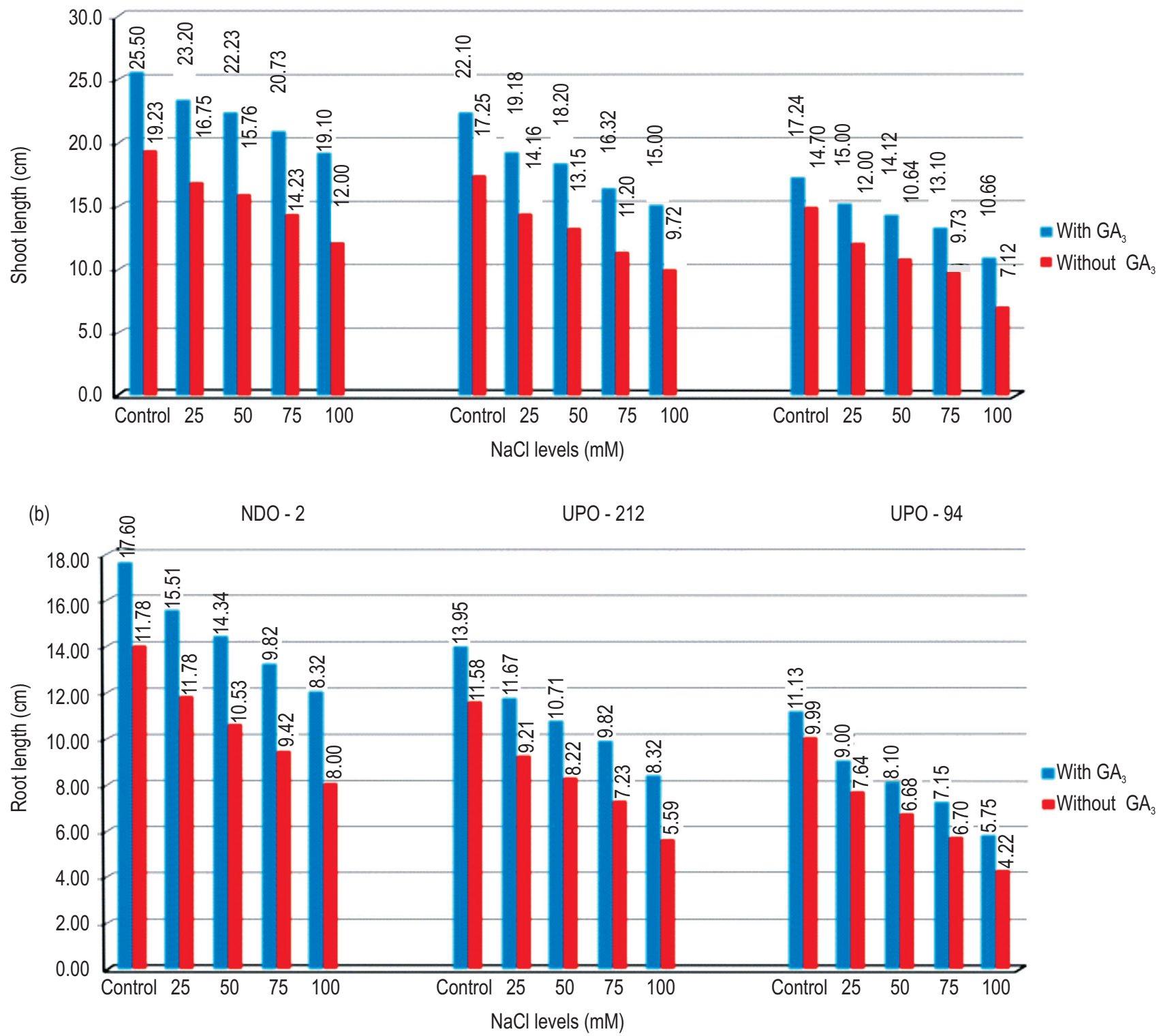

Fig. 2 : Interactive effects of salinity and $\mathrm{GA}_{3}$ on (a) shoot length and (b) root length on three cultivars of oat ; (Without $\mathrm{GA}_{3}$ all salt treatment (25, 50, 75 and $100 \mathrm{mM}$ ) was compared with control; $\mathrm{GA}_{3}$ + salt treatment was compared with $\mathrm{NaCl}$ treatment. Application of $\mathrm{GA}_{3}$ significantly promoted the length of shoot and root under saline conditions)

to $42.82 \%$ ) in cv. NDO-2 was recorded respectively in shoot and root length at 25 to $100 \mathrm{mM} \mathrm{NaCl}$ concentrations. The present results indicate that shoot and root length in different oat cultivars reduced significantly with increasing salinity levels from 25 to 100 $\mathrm{mM}$. These results are in agreement with those of Akbarimoghaddam et al. (2011) who showed that $\mathrm{NaCl}$ salinity caused a marked reduction in shoot and root lengths. Salt stress reduced the ability of plants to absorb water which leads to reduction in growth (Nawaz et al., 2010). The inhibitory effect of salinity on growth rate and development of seedlings was reported by Rajput et al. (2015) in castor bean. Salt stress reduced the ability of plants to absorb water which leads to reduction in growth (Nawaz et al., 2010). Applications of $\mathrm{GA}_{3}$ significantly promoted the length of shoot and root in all the cultivars of oat at all salinity treatments. Tolerant cultivar NDO-2 showed the maximum height (25.50 to $19.10 \mathrm{~cm}$ and 17.60 to $11.99 \mathrm{~cm}$ ) and minimum height was found in sensitive cv. UPO-94 ranging from 17.24 to $10.66 \mathrm{~cm}$ and 11.13 to $5.75 \mathrm{~cm}$ in shoot and root length respectively, at varying salinity levels $\left(25\right.$ to $100 \mathrm{mM}$ ) including control. $\mathrm{GA}_{3}$ treated oat plants showed an increase in tolerance to salt 
Table 2: Effects of gibberellic acid on chlorophyll contents a and $b$ ( $\mathrm{mg} \mathrm{g}^{-1} \mathrm{f}$.wt.) in three oat cultivars under salinity stress

\begin{tabular}{llll}
\hline Cultivars & \multicolumn{3}{c}{ Mean difference ( with $\mathrm{GA}_{3-}$ without $\mathrm{GA}_{3}$ ) } \\
\cline { 2 - 4 } & Chlorophyll 'a' & Chlorophyll ' $b$ ' & Chlorophyll $a+b$ \\
\hline NDO-2 & $0.12 \pm 0.007^{*}$ & $0.05 \pm 0.005^{*}$ & $0.17 \pm 0.011^{*}$ \\
UPO-212 & $0.08 \pm 0.005^{*}$ & $0.03 \pm 0.004^{*}$ & $0.11 \pm 0.005^{*}$ \\
UPO-94 & $0.06 \pm 0.014^{*}$ & $0.02 \pm 0.005^{\text {ns }}$ & $0.08 \pm 0.009^{*}$
\end{tabular}

Values are mean of four replicates \pm SD; Data subjected to paired sample ' $t$ ' test; ${ }^{(*)}$ significant at 0.05 level; ${ }^{(n s)}$ non-significant
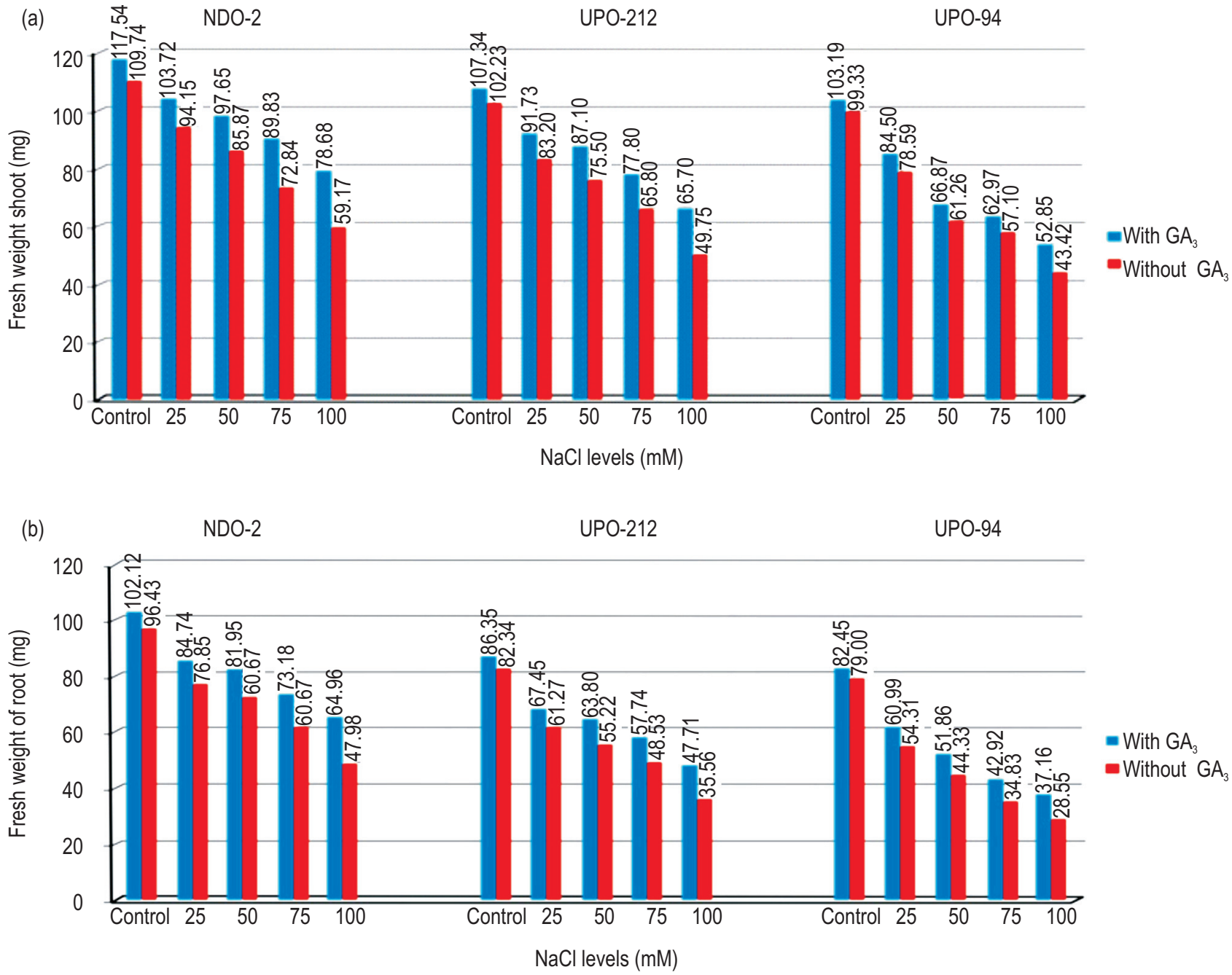

Fig. 3 : Interactive effects of salinity and $\mathrm{GA}_{3}$ on (a) fresh weight of shoot and (b) fresh weight of root on three cultivars of oat; (Without $\mathrm{GA}_{3}$ all salt treatment $\left(25,50,75\right.$ and $100 \mathrm{mM}$ ) was compared with control; $\mathrm{GA}_{3}+$ salt treatment was compared with $\mathrm{NaCl}$ treatment. Application of $\mathrm{GA}_{3}$ significantly promoted the fresh weight of shoot and root under saline conditions)

treatment. This increase in salt tolerance was reflected in growth. Length of shoot and root was increased when compared with nontreated plants. The effect of $\mathrm{GA}_{3}$ was also consistent over salinity levels and gibberellic acid alleviated the harmful effects of salinity and enhanced plant height. Javid et al., (2011) and Shaddad et al.,
(2013) also reported a similar increase in the growth of shoot and root of soybean plants in response to $\mathrm{GA}_{3}$ treatment. Bejaoui (1985) has reported that the effects of exogenously applied $\mathrm{GA}_{3}$ in alleviation of salt stress may be caused by activation of special enzymes which participate in RNAand protein synthesis. 

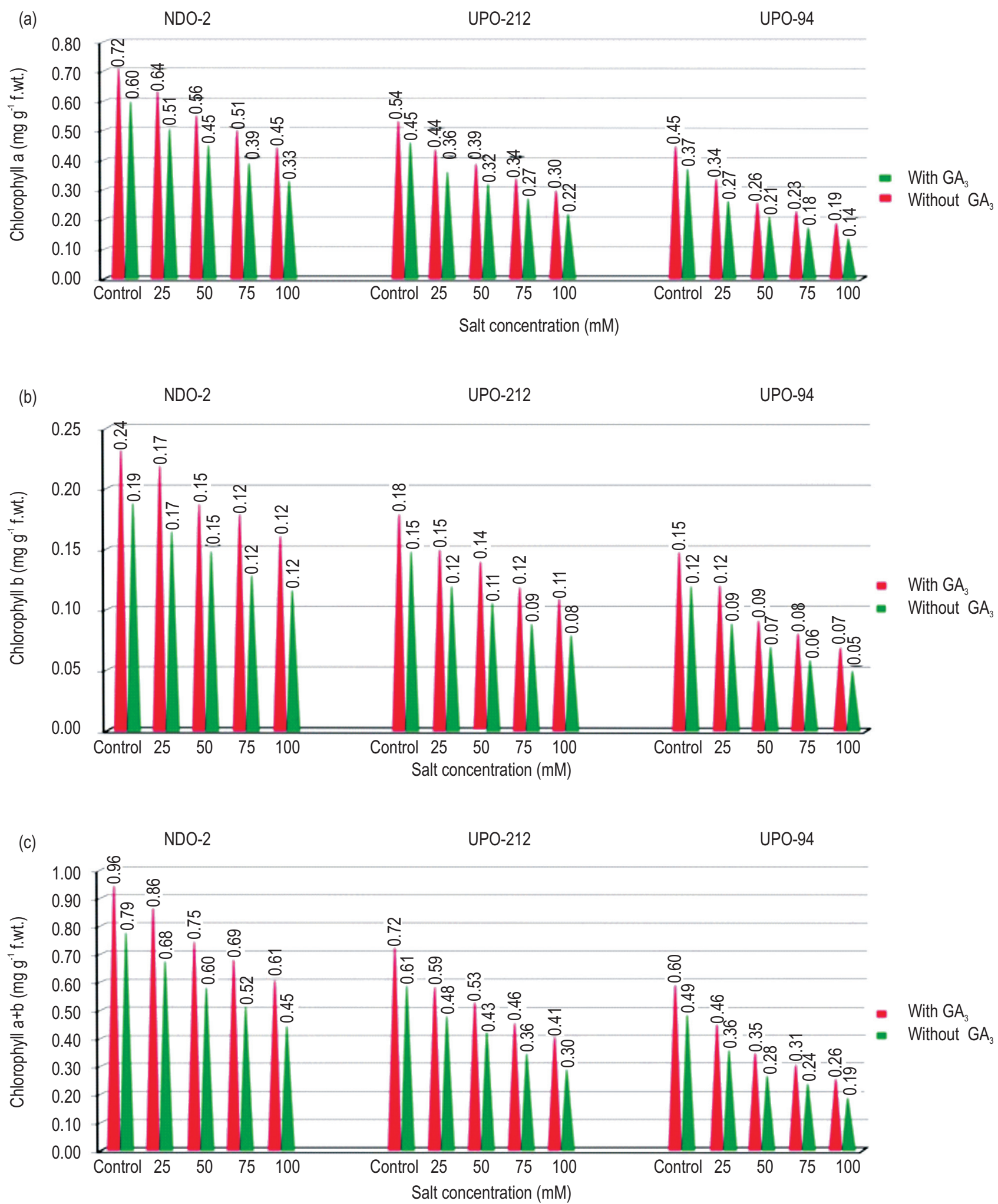

Fig. 4 : Interactive effects of $\mathrm{GA}_{3}$ and salt stress on (a) Chl a; (b) Chl. b and (c) Chl. (a+b) on three cultivars of oat; (Without GA ${ }_{3}$ all salt treatment (25, 50, 75 and $100 \mathrm{mM}$ ) was compared with control; $\mathrm{GA}_{3}+$ salt treatment was compared with $\mathrm{NaCl}$ treatment. Exogenous application of $\mathrm{GA}_{3}$ significantly increased the chlorophyll contents under salt concentrations (25 to $100 \mathrm{mM}$ ). Cv. NDO-2 performed better under salinity stress when application of $\mathrm{GA}_{3}$ was given.) 
Interactive effects of $\mathrm{GA}_{3}$ and $\mathrm{NaCl}$ salinity stress on fresh weight of shoots and roots is shown in fig. $3(a, b)$. Data indicated that $\mathrm{CV}$. NDO-2 and UPO-212 statistically significant paired differences (with and without $\mathrm{GA}_{3}$ ) in fresh weight of shoot and root, respectively, at all levels of salinity including control (Table. 1). The highest fresh weight of shoot and root were obtained in cv. NDO-2 and lowest in cultivar UPO-94 at all salinity levels. At 25 to $100 \mathrm{mM}$ saline concentrations, the fresh weight of shoot and root was highly reduced in cv. UPO-94. It ranged from 20.88 to $56.29 \%$ and 31.25 to $63.86 \%$ in shoot and root respectively. Cv. NDO-2 showed lower reduction (14.13 to $51.34 \%$ and 20.30 to $56.36 \%$ followed by UPO-212 (18.61 to $26.15 \%$ and 25.59 to $50.24 \%$ ) in fresh weight of shoot and root at these salinity levels. The fresh weight of shoot and root also showed a considerable decrease at higher salinity levels. However, roots were more sensitive to salinity as compared to shoots. These results are similar to those reported by Agarwal et al. (2015), in soybean. Reduction in fresh biomass at higher concentration might be due to poor absorption of water from the growth medium due to physiological drought (Nedjimi et al., 2006; Seckin et al., 2009). Fresh weights were decreased with an increase in the level sodium chloride as a result of reduced photosynthesis and membrane stability (Mozafariyan et al., 2013). Under $\mathrm{GA}_{3}$ treatment, cv. UPO-94 showed greater reduction ( 18.11 to $48.78 \%$ and 26.03 to $54.93 \%$ ) while lesser reduction (11.76 to $33.06 \%$ and 17.02 to $36.39 \%$ ) was achieved in cv. NDO-2 followed by UPO-212 (14.54 to $38.79 \%$ and 21.89 to $44.75 \%$ ) on fresh weight of shoot and root, respectively, at all salinity levels (25 to $100 \mathrm{mM}$ ). In oat waterdeficit and salt treatments also caused reduction in seedling fresh weight, which is similar to several reports (Agarwal and Panday, 2004; Ramezani et al., 2011). Exogenous application of $\mathrm{GA}_{3}$ was promoted, generally growth parameters (fresh weight of shoot and root) of oat plants, thus alleviating to some extent the oppressive effect of salinity (Abd El-Samad and Shaddad, 2013).

The effect of $\mathrm{GA}_{3}$ on chlorophyll contents of oat cultivars under different saline concentrations is shown in Fig. $4(a, b, c)$. Chlorophyll $a$ and $b$ was higher in tolerant cv. NDO-2 ( 0.60 to 0.33 and 0.19 to $0.12 \mathrm{mg} \mathrm{g}^{-1} \mathrm{f}$.wt.) and lower in sensitive $\mathrm{cv}$. UPO-94 ( 0.37 to 0.14 and 0.12 to $0.05 \mathrm{mg} \mathrm{g}^{-1} \mathrm{f}$.wt.) at all salinity levels as compared to control. However, chlorophyll $b$ was more sensitive than chlorophyll $a$. The maximum chlorophyll $(a+b)$ was observed in NDO-2 and minimum in UPO-94 at 25 to $100 \mathrm{mM}$. In this study, chlorophyll contents were significantly decreased with the increase of salinity levels in all cultivars of oat. Consistent with these results, Khalid and Cai (2011); Celik and Atak (2012) found an inhibition in chlorophyll bio synthesis in sorghum due to salt stress. The decrease may be due to the formation of proteolytic enzymes such as chlorophyllase, which is responsible for chlorophyll degradation (Sabater and Rodriguez, 1978). Application of $\mathrm{GA}_{3}$ improved the chlorophyll levels in salinitystressed plants of oat. $\mathrm{GA}_{3}$ treated plants exhibited higher values of chlorophyll contents in tolerant cultivar NDO-2 as compared to other cultivars. Similarly, Datta et al., (2009) observed that $\mathrm{GA}_{3}$ treatment increased chlorophyll contents as well as the rate of photosynthesis in soybean plants. $\mathrm{GA}_{3}$ treatment alleviated the negative effects of salinity on the morphological traits and physiological attributes such as chlorophyll content and stomatal conductance (Misratia et al., 2013 and Nikee et al., 2014).

It is concluded from the present investigation that exogenous application of $\mathrm{GA}_{3}$ might counteract the adverse effect of salinity. NDO-2 and UPO-212 proved to have better growth and high chlorophyll contents as compared to UPO-94 when seedling were treated with $\mathrm{GA}_{3}$ under different salinity conditions. On the other hand, the inhibitory and deleterious effects of salinity (the plants irrigated with saline water) seemed to be decreased by application of $\mathrm{GA}_{3}$.

\section{Acknowledgments}

We express my sincere thanks to Dr. Nikhil Rastogi, Director of SOS, IFTM University, Moradabad for providing laboratory and library facilities to carry out the research work. The authors are thankful to Dr. Anamika Tripathi, Associate Professor, Department of Botany, Hindu College, Moradabad. Her timely advice and meticulous scrutiny was helpful to accomplish this research.

\section{References}

Abd El-Samad, H. and M.A.K. Shaddad: The exogenous amelioration roles of growth regulators on crop plants grow under different osmotic potential. J. Stress Phys. Bioch., 1, 34-57 (2013).

Agarwal, N., A. Kumar, S. Agarwal and A. Singh: Evaluation of soybean (Glycine max L.) cultivars under salinity stress during early vegetative groath. Int. J. Current Microbiol. App. Sci., 4, 123-134 (2015).

Agarwal, S. and V. Panday: Antioxidant enzyme responses to $\mathrm{NaCl}$ stress in Cassia angustifolia. Biol. Plant, 48, 555-560 (2004).

Akbarimoghaddam, H., M. Galavi, A. Ghanbari and N. Panjehkeh: Salinity effects on seed germination and seedling growth of bread wheat cultivars. Trakia. J. Sci., 9, 43-50 (2011).

Akca, Y. and E. Samsunlu: The effect of salt stress on growth, chlorophyll content proline and nutrient accumulation and $\mathrm{K} / \mathrm{Na}$ ratio in Walnut. Pakistan J. Botany, 44, 1513-1520 (2012).

Arnon, D.I.: Copper enzymes in isolated chloroplasts, polyphenoxidase in Beta vulgaris. Plant Phys., 24, 1-15 (1949).

Ashraf, M. and P.J.C. Harris: Potential biochemical indicators of salinity tolerance in plant. Plant Sci., 166, 3-16 (2004).

Ashraf, M. and P.J.C. Harris: Photosynthesis under stressful environments: An overview. Photosynthetica, 51,163-190 (2013).

Ashraf, M., H.R. Ather, P.J.C. Harris and T.R. Kwon: Some prospective strategies for improving crop salt tolerance. Adv. Agro., 97, 45-110 (2008).

Baskin, C.C. and J.M. Baskin: Seeds: Ecology, biogeography and evolution of dormancy and germination. $2^{\text {nd }}$ Edn., Elsevier IAcademic Press, San Diego, CA, USA(2014).

Bejaoui, M: Interaction between $\mathrm{NaCl}$ and some phytohormones on soybean growth. J. Plant Physiol., 120, 95-110 (1985). 
Benliglu, B. and U. Ozkan: Determination of responses of some oat cultivars (Avena sativa L.) to salt and drought stress at the germination period. Ciencia e Tecnica Vitivinicola J., 31, 6-25 (2016).

Celik, O. and C. Atak: The effect of salt stress on antioxidant enzymes and proline content of two Turkish tobacco varieties. Turk. J. Biol., 36, 339-356 (2012).

Chauhan, A., N. Rajput, D. Kumar, A. Kumar and A.K. Chaudhry: Effect of different salt concentration seed germination and seedling growth of different varieties of oat (Avena sativa L.). Int. J. Inform. Res. Rev., 3, 2627-2632 (2016).

Datta, J.K., S. Nag, A. Banerjee and N.K. Mondal: Impact of salt stress on five varieties of wheat (Triticum aestivum L.) cultivars under laboratory condition. J. Appl. Sci. Environ. Manage., 13, 93-97 (2009).

El-Sabagh, A.R., A.E. Omar, H. Saneoka and C. Barutcular: Physiological performance of soybean germination and seedling growth under salinity stress. Dicle Univ. Instit. Nat. Appl. Sci. J., 4, 6-15 (2016).

El-Shaieny, A.H.: Seed germination percentage and early seedling establishment of five (Vigna unguiculata L. (Walp) genotypes under salt stress. European J. Exp. Biol., 5, 22-32 (2015).

Flexas, J., A. Diaz-Espejo, J. Galmés, R. Kaldenhoff, H. Medrano and M. Ribas-Carbo: Rapid variations of mesophyll conductance in response to changes in $\mathrm{CO}_{2}$ concentration around leaves. Plant Cell Environ., 30, 1284-1298 (2007).

Ghodrat, V. and M.J. Rousta: Effect of priming with gibberellic acid $\left(\mathrm{GA}_{3}\right)$ on germination and growth of corn (Zea mays L.) under saline conditions. Int. J. Agric. Crop Sci., 4, 883-885 (2012).

Gioria, M., P. Pysek and B.A. Osborne: Timing is everything: Does early and late germination favour invasions by herbaceous alien plants. J. PlantEcol., 61, 2-13 (2016).

Gurung, N., G.S.K. Swamy, S.K. Sarkar and N.B. Ubale: Effect of chemicals and growth regulators on germination, vigour and growth of passion fruit (Passiflora edulis sims.). Bioscan, 9, 155157 (2014).

Hasegawa, P., R.A. Bressan, J.K. Zhu and H.J. Bohnert: Plant cellular and molecular responses to high salinity. Annu. Rev. Plant Physiol. Plant Mol. Biol., 51, 463-499 (2000).

Jaleel, C.A., R. Gopi, P. Manivannan and R. Paneerselvem: Soil salinity alters the morphology in Catharanthus roseus and its effects on endogenous mineral constituents. Eurasian J. Biosci., 2, 18-25 (2008).

Jasmine, M.S. and M.A. John: Effects of gibberellic acid on seedling growth, chlorophyll content and carbohydrate metabolism in okra (Abelmoschus esculentus $L$ Moench) under saline stress. Res. J. Che. Sci., 2, 72-74 (2012).

Javid, M.G., A. Sorooshzadeh, F. Moradi, S.A. Sanavy and I. Allahdadi: The role of phytohormones in alleviating salt stress in crop plants. Aust. J. Crop Sci., 5, 726-734 (2011).

Kaveh, H., H. Nemati, M. Farsi and S.V. Jartoodeh: How salinity affect germination and emergence of tomato lines. J. Biol. Environ. Sci., 5, 159-163 (2011).

Khalid, A. and W. Cai: The effects of mannitol and salinity stresses on growth and biochemical accumulations in lemon balm. Acta. Ecologica Sinica, 31, 112-120 (2011).

Kumar, A., S. Agarwal and A. Singh: Salinity effects the germination and seedling growth in some cultivars of oat (Avena sativa L.). Indian J.
Adv. Plant Res., 1, 1-10 (2014).

Misratia, K.M., M.R. Ismail, M.A. Hakim, M.H. Musa and P. Adam: Effect of salinity and alleviating of gibberellic acid $\left(\mathrm{GA}_{3}\right)$ for improving the morphological, physiological and yield traits of rice varieties. Aust. J. Crop Sci., 7, 1682-1692 (2013).

Misratia, K.M., M.R. Islam, M.R. Ismail, F.C. Oad, M.M. Hanafi and A. Puteh: Interactive effects of gibberellic acid $\left(\mathrm{GA}_{3}\right)$ and salt stress on growth and ion accumulation of two rice (Oryza sativa L.) varieties differing in salt tolerance. J. Food Agric. Environ., 13, 6670 (2015).

Mozafariyan, M., K. Saghafi, A.E. Bayat and S. Bakhtiari: The effects of different sodium chloride concentrations on the growth and photosynthesis parameters of tomato (Lycopersicum esculentum cv. Foria). Int. J. Agric. Crop. Sci., 6, 203-207 (2013).

Nawaz, K., K. Hussain., A. Majeed, F. Khan, S. Afghan and K. Ali: Fatality to salt stress to plants: Morphological, physiological and biochemical aspects. Afr. J. Biotech., 9, 5475-5380 (2010).

Nedjimi, B., Y. Daoud and M. Touati: Growth, water relation, proline and ion content of invitro cultured Atriplex halimus subsp. Schweinfurthi as affected by $\mathrm{CaCl}_{2}$. Comm. Biometry Crop Sci., 2, 79-89 (2006).

Nikee, E., A. Pazoki and H. Zahedi: Influences of ascorbic acid and gibberellin on alleviation of salt stress in summer savory (Satureja hortensis L.). Int. J. Biosci., 5, 245-255 (2014).

Pandey, K.C. and A.K. Roy: Forage crops varieties. Ind. Grassland and Fodd. Res. Ins., 283003 (U.P) (2010).

Parvaiz, A. and S. Satyawati: Salt stress and phyto-chemical responses of plants. Plant Soil Environ., 4, 89-99 (2008).

Patel, R.G. and A.U. Mankad: Effect of gibberellins on seed germination of Tithonia rotundifolia Black. Int. J. Innov. Res. Sci., 3, 1068010683 (2014).

Rajput, N., A. Kumar and A.K. Chaudhry: Effects of $\mathrm{NaCl}$ stress on seed germination and early seedling growth of castor bean (Ricinus communis L.). Int. J. Scie. Res., 11, 104-107 (2015).

Ramezani, E., M.G. Sepanlou and H.A.N. Badi: The effect of salinity on the growth, morphology and physiology of Echium amoenum Fisch \& Mey. Afric. J. Biotech., 10, 8765-8773 (2011).

Sabater, B. and M.I. Rodriguez: Control of chlorophyll degradation in detached leaves of barley and oat through effect of kinetin on chlorophyllase levels. Physiol. Plant., 43, 274-276 (1978).

Seckin, B., A.H. Sekmen and I. Turkan: An enhancing effect of exogenous mannitol on the antioxidant enzyme activities in root of wheat under salt stress. J. Plant Growth Regul., 28, 12-20 (2009).

Shaddad, M.A.K., H.M. Abd El-Samad and D. Mostafa: Role of gibberellic acid in improving salt stress tolerance of two wheat cultivars. Int. J. Plant Physiol. Biochem., 5, 50-57 (2013).

Shrivastava, P. and R. Kumar: Soil salinity: A serious environmental issue and plant growth promoting bacteria as one of the tools for its alleviation. Saudi J. Biological Sci., 22, 123-131 (2015).

Zhang, H., L.J. Irving, C. McGill, C. Matthew, D. Zhou and P. Kemp: The effects of salinity and osmotic stress on barley germination rate: Sodium as an osmotic regulator. Ann. Bot., 106, 1027-1035 (2010).

Zhang, X.Q., Z.Y. Lu, Y.C. Cheng, X.X. Guo, L. Tian, J.Z. Zhang, F. Xian and P.C. He: Effects of mixed salt stress on germination percentage and protection system of oat seedling. Adv. J. Food Sci. Tech., 592, 197-205 (2013). 